\title{
Cidades na Amazônia: Centralidades e Sistemas territoriais na sub-região do Baixo Amazonas (AM)
}

Amazon cities: centralities and territorial systems in the Lower amazon subregion, Amazonas State (AM)

Villes amazoniennes : centralité et systèmes territoriaux dans la sous-région du Bas Amazonas (AM)

Ciudades en la Amazonia: centralidades y sistemas territoriales en la subregión del Bajo Amazonas (AM)

\section{Estevan Bartoli}

\section{OpenEdition}

Journals

\section{Edição electrónica}

URL: http://journals.openedition.org/espacoeconomia/17823

DOI: 10.4000/espacoeconomia.17823

ISSN: 2317-7837

Editora

Núcleo de Pesquisa Espaço \& Economia

Refêrencia eletrónica

Estevan Bartoli, "Cidades na Amazônia: Centralidades e Sistemas territoriais na sub-região do Baixo Amazonas (AM)», Espaço e Economia [Online], 20 | 2020, posto online no dia 07 janeiro 2021, consultado o 29 janeiro 2021. URL: http://journals.openedition.org/espacoeconomia/17823 ; DOI: https://doi.org/10.4000/espacoeconomia.17823

Este documento foi criado de forma automática no dia 29 janeiro 2021.

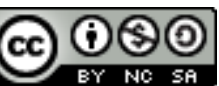

Espaço e Economia - Revista brasileira de geografia econômica est mise à disposition selon les termes de la licence Creative Commons Attribution - Pas d'Utilisation Commerciale - Partage dans les Mêmes Conditions 4.0 International. 


\title{
Cidades na Amazônia: Centralidades e Sistemas territoriais na sub-região do Baixo Amazonas (AM)
}

\author{
Amazon cities: centralities and territorial systems in the Lower amazon sub- \\ region, Amazonas State (AM) \\ Villes amazoniennes : centralité et systèmes territoriaux dans la sous-région du \\ Bas Amazonas (AM) \\ Ciudades en la Amazonia: centralidades y sistemas territoriales en la subregión \\ del Bajo Amazonas (AM)
}

Estevan Bartoli

\section{Introdução}

1 O artigo objetiva traçar o perfil socioeconômico dos municípios da sub-região do Baixo Amazonas (AM) visando demonstrar características comuns, articulações e fragmentações no desenvolvimento desigual da rede urbana. Originalmente desenvolvido para explicar a dinâmica urbana de Parintins (AM), o modelo relativo ao Sistema Territorial Urbano-Ribeirinho (STUR) é aplicado em todos os municípios do Baixo Amazonas ${ }^{1}$, cujos resultados parciais são demonstrados neste texto ${ }^{2}$.

2 Os procedimentos metodológicos foram pautados na revisão da literatura sobre urbanização na Amazônia que nos fornece base para o entendimento dos processos e dinâmicas da rede urbana e suas diversas articulações escalares, fragmentações e desigualdades. A coleta de dados ocorreu em instituições diversas, trabalhos de campo com aplicação de formulários e entrevistas a lideranças locais como presidentes de associações, Colônias de pescadores, sindicatos rurais e demais redes de sujeitos de destaque nas economias locais. Tabelas, quadros comparativos e mapas nos servem para demonstrar o comportamento espacial das redes de sujeitos locais e as centralidades das sedes municipais. 
3 No primeiro momento se realiza considerações teóricas sobre o processo de urbanização regional apresentando reflexões sobre a urbanização incompleta através de dados socioeconômicos que evidenciam a estagnação dos municípios.O segundo subitem analisa características comuns que conferem coesão e as desarticulações subregionais, utilizando dados secundários sobre comércio, serviços, população e PIB. Junto a constatações de campo e análise de mapas descrevemos padrões de deslocamentos e centralidade das cidades.

4 No terceiro item apresenta-se o modelo teórico-metodológico relativo ao Sistema Territorial Urbano-Ribeirinho (STUR) que compreende análise da dinâmica de setores populares da economia urbana em interação com o capital mercantil. Apresenta ainda os principais subsistemas territoriais existentes nos municípios concluindo que existe um padrão espacial semelhante no ordenamento territorial das cidades assim como fragmentações e descontinuidades causadas por dinâmicas escalares.

\section{Considerações sobre o processo urbano na Amazônia}

5 Nossa hipótese norteadora afirma que a aceleração do processo urbano associado a novas variáveis (difusão do consumo, principalmente) interagem com formações socioespaciais herdadas, alterando as funções das cidades e reduzindo seus papeis econômicos. Tal processo torna ainda mais frágil as inserções entre os municípios no quadro regional bastante desigual devido ao modelo implantado desde o advento da Zona Franca de Manaus (hoje Polo Industrial).

Em seus percursos evolutivos as cidades na Amazônia estiveram vinculadas a formas de dominação, concentração geográfica e social de um excedente de produção e deslocamento de populações, sendo a urbanização uma estratégia do capital para ocupar e controlar rapidamente a fronteira (GENTIL, 1988). Nesse processo, o destino das populações das cidades aparece como elemento central, onde a urbanização da fronteira é "desarticulada do seu próprio desenvolvimento e vai além dos limites internos de crescimento que a velocidade do desenvolvimento da região pode impor" (BROWDER; GODFREY, 2006). Não olvidemos como aponta Becker (2005), que a economia amazônica é "reflexa" de vieses econômicos mundiais, cujos desdobramentos da influência global multiescalar na rede urbana tem sido objeto de estudos diversos (TRINDADE JR., 2010; MONTE MÓR, 1994; BROWDER e GODFREY, 2006; BECKER, 2005; 2013). A gênese da rede urbana e sua inserção em ciclos econômicos de produção/ extração de mercadorias estiveram vinculadas às demandas da economia-mundo (WALLERSTEIN, 1985), cuja valorização flutua com as transformações e reveses que a economia global impõe.

7 Sobre o caráter desigual do processo de desenvolvimento capitalista, Becker (2013) afirma que o não desenvolvimento das cidades na região tem explicação na ausência de novas divisões de trabalho que poderiam estimular trocas comerciais e incentivar substituição de importações. Uma nova divisão territorial do trabalho poderia reorganizar a rede urbana para criação de relações mútuas entre as cidades, rompendo assim vias hierárquicas que dominam núcleos urbanos. Para a autora essa falha persiste criando ausência de agregação de valor aos produtos exportados sendo "uma das principais razões da insuficiência de dinamismo urbano. As pequenas manufaturas geradas logo sucumbiram com o declínio do surto (BECKER, 2013 - p. 19)". 
8 Browder e Godfrey (2006) afirmam que os vetores de atividades ditas "modernas" incidem diferencialmente nos diversos subespaços regionais e fragmentam relações, constituindo rede de cidades que não possui um princípio geral de organização e é caracterizada como desarticulada de um princípio geral de ordenamento. A tese dos autores relativa à urbanização desarticulada enfatiza padrões de desenvolvimento que certas localidades e pequenos centros urbanos possuem, estando vinculados a valorizações momentâneas de produtos primários oriundos do extrativismo, que atingiriam o auge de suas atividades e depois tiveram queda acentuada ("boom-bust"), apresentam declínio populacional e migrações constantes para novos centros, constituindo uma verdadeira fronteira móvel.

9 A maneira com que antigos padrões de circulação e extração de excedentes se comportam frente às recentes mudanças relacionadas ao processo de urbanização / globalização constitui ampla questão, que se desdobra em outras: Qual seria a capacidade de mediação no ordenamento territorial que tais núcleos urbanos possuem hoje? Frente ao quadro de estagnação sub-regional, como a ampliação do consumo reforça papeis de lugares centrais em cidades com economias de baixa complexidade? Quais são as redes de sujeitos e como suas práticas territoriais reinserem o papel dos núcleos urbanos numa nova divisão territorial do trabalho?

10 Nesse contexto, populações urbanas empobrecidas constroem territorialidades ao interagir com as possibilidades e limites impostos pelo processo urbano. Da mesma maneira, setores dominantes locais diversificam suas estratégias de acumulação de riquezas com base nas atividades urbanas. Essa reterritorialização de setores populares / classes dominantes, age sobre o sedimento territorial sub-regional estabelecendo padrões de uso de recursos locais e modos de circulação que possuem os aspectos físicos regionais como fortes condicionantes (impactos das cheias / vazantes, por exemplo). As sedes são utilizadas enquanto nós multireticulares para extração (com raros processamentos), desses recursos regionais. Seriam rudimentares permanências redinamizadas por novos vetores, com formas de exploração e uso do território apresentando novos conteúdos.

11 Além da baixa capacidade de processamento de recursos regionais e não formação de divisões territoriais do trabalho e trabalho novo (FERNANDES, 2009), outras características comuns entre os municípios do Baixo Amazonas emergem. $O$ elevado desemprego urbano, renda e PIB per capta baixos, a dependência de repasses governamentais (tabela 1) e uma produção rural pouco significativa. Esse processo foi acentuado pela criação da Zona Franca de Manaus e a posterior formação do Polo Industrial (BECKER, 1974), que impactou negativamente as economias de pequenas cidades interioranas. Mesmo com boas intenções do Planejamento Estratégico da SUFRAMA para aprimorar o processo de interiorização dos efeitos do modelo Zona Franca de Manaus e fomentar a produção no interior da região (SUFRAMA, 2007, p.13), as desigualdades espaciais se aprofundaram como demonstra a tabela 1. É latente a disparidade de população, renda, esgotamento sanitário e desenvolvimento humano entre a capital Manaus comparada às cidades do Baixo Amazonas, ou até mesmo com a segunda cidade mais populosa do estado, Parintins. 
Tabela 1 - Comparativo das características sociodemográficas dos municípios do Baixo Amazonas com a capital Manaus.

\begin{tabular}{|l|l|l|l|l|l|}
\hline Municípios & População & $\begin{array}{l}\text { PIB per } \\
\text { capta }\end{array}$ & IDH & $\begin{array}{l}\text { Mortalidade infantil } \\
\text { (óbitos por mil nascidos } \\
\text { vivos) }\end{array}$ & $\begin{array}{l}\text { Esgotamento } \\
\text { sanitário adequado }\end{array}$ \\
\hline Urucará & 16.383 & $17.378,65$ & 0,620 & 11,11 & $10,9 \%$ \\
\hline $\begin{array}{l}\text { Boa Vista do } \\
\text { Ramos }\end{array}$ & 18.781 & $\begin{array}{l}6.089,15 \\
\mathrm{R} \$\end{array}$ & 0,565 & 12,54 & $29,7 \%$ \\
\hline Barreirinha & 31.593 & $\begin{array}{l}7.059,80 \\
\mathrm{R} \$\end{array}$ & 0,574 & 14,94 & $4,3 \%$ \\
\hline $\begin{array}{l}\text { S. Sebastião do } \\
\text { Uatumã }\end{array}$ & 13.685 & $7.232,53$ & 0,577 & 19,42 & $1,7 \%$ \\
\hline Nhamundá & 20.899 & $6.462,02$ & 0,586 & 16,76 & $16,1 \%$ \\
\hline Maués & 62.755 & $6.481,40$ & 0,588 & 16,74 & $27,1 \%$ \\
\hline Parintins & 113.168 & $9.092,68$ & 0,658 & 22,91 & $19,3 \%$ \\
\hline Manaus & 2.145 .444 & $33.564,11$ & 0,737 & 14,52 & $62,4 \%$ \\
\hline
\end{tabular}

Fonte: IBGE Cidades (2019) - organizado pelo autor.

O predomínio do modelo pautado no Polo Industrial conferiu a Manaus concentrar metade da população e $78 \%$ do PIB do estado, acarretando enorme estagnação do setor rural dos interiores por falta de apoio. Associado ao constante êxodo tornou as economias locais incapazes de incentivar a economia formal e novas divisões territoriais do trabalho mais complexas. Desenha-se contexto típico de urbanização incompleta nos interiores, termo usado por Milton Santos (1993) para descrever a urbanização em países periféricos. O que "completa" a manutenção da vida dessas populações é a constante interpenetração entre o "urbano e o ribeirinho".

Milton Santos (2007), tecendo a relação entre espaço e dominação, coloca a urbanização como nervo essencial de intermediação. Os produtos mais caros recebem primazia no transporte quando há choque com outras safras, gerando desvalorização de certas atividades em favor de outras. A especialização geográfica da produção passa a ser responsável por uma massificação do capital, gerando alienação regional e alienação do homem-produtor. Ressalta ainda que a especialização regional é simultânea a uma especialização urbana, na qual a massificação do capital causa colapso em cidades locais (Ibid, p134).

Aplicamos formulários a proprietários de embarcações pequenas e médias pertencentes ao Sistema Territorial Urbano-Ribeirinho em cinco municípios do Baixo Amazonas entre fevereiro e dezembro de 2019: Parintins, Barreirinha, Nhamundá, Urucará e São Sebastião do Uatumã. Devido à pandemia do Covid-19, os trabalhos de campo foram interrompidos. Os formulários aplicados são padronizados permitindo comparações entre os municípios, contemplando análise de: atividades laborais rurais e urbanas, 
frequência do acesso à cidade, tipos de vínculos com comunidades, produtos absorvidos pela cidade/levados para o interior (figura 1) e relações com o sítio urbano e sazonalidade. Os resultados sobre Parintins, Urucará, Barreirinha e São Sebastião do Uatumã foram apresentados em Bartoli (2018a, 2018b, 2019, 2020a, 2020b). Os sujeitos entrevistados nas beiras de rio são pescadores, agricultores, pequenos criadores de gado e comerciantes. Muitos deles realizam várias tarefas laborais, complementando renda ainda com atividades urbanas em serviços gerais, sendo uma das características mais marcantes das redes de sujeitos dinamizando o STUR. Os dados obtidos revelam que populações ao acessarem a cidade para usufruir das "benesses urbanas" (sistema de saúde, de educação, comércio local, etc.), acabam retornando aos interiores com uma série de produtos industrializados adquiridos nos comércios locais, configurando aspectos do processo da urbanização extensiva (MONTE-MÓR, 1994). Essa demanda de alimentos no mercado urbano vem alterando cada vez mais itens da dieta regional, sendo marcante a presença crescente de conserva, frango congelado, embutidos e outros produtos industrializados (MORAES e SCHOR, 2010; MORAES, 2014).

Inserimos aqui, reflexão sobre variáveis importantes na reconfiguração urbana que estamos tratando, relacionadas ao consumo urbano com intensificação da circulação, cujas relações escalares denotam projeções de poder de empresas transnacionais sobre o território amazônico. Considerando a competição inter-regional no interior do espaço brasileiro, assim como as transformações do cenário econômico nacional/ internacional, Brandão (2007) afirma que Estudos regionais e urbanos devem caracterizar os resultados da sensibilidade diferencial das regiões à crise. $O$ autor faz alerta para análise das forças coercitivas exógenas e macroeconômicas como concorrências/rivalidades entre agentes capitalistas e forças oligopólicas, por exemplo, pois o comando maior desse processo está fora dos espaços de análise "tornando-se impositivo estudar a natureza das hierarquias (impostas em variadas escalas) de geração e apropriação de riqueza" (BRANDÃO, 2007, p. 48). Essa desigual capacidade de competição tem legado a estagnação econômica de cidades pequenas nos interiores da Amazônia, com redefinições dos papeis e funções.

\section{Características da sub-região do Baixo Amazonas: aspectos comuns e desarticulações}

Objetivo do presente item é elencar características socioespaciais da sub-região em questão considerando as cidades enquanto construções históricas relacionadas à totalidade das relações capitalistas. A escolha do recorte espacial da sub-região de planejamento se deve a dois critérios. O primeiro é operacional, relativo ao papel de instituições diversas ${ }^{3}$ para repensar políticas públicas de desenvolvimento territorial, cujo recorte privilegia municípios do estado do Amazonas. Visa-se analisar o urbano na sua dimensão regional, reconhecendo as distinções a partir das regiões que as geram como proposto em Bitoun (2009) onde as tipologias de cidades associadas a outras estratégias de desenvolvimento territorial fornecem auxílio nas especificações de propostas em políticas públicas.

17 Essa delimitação operacional não significa deixar de lado as "porosidades", fluxos e interações multiescalares e as desarticulações e fragmentações. Considerar as conexões com a rede paraense é essencial (BARTOLI, 2018a), no sentido da polarização exercida sobre a rede amazonense. $\mathrm{O}$ "delimitar" requer entender as fragmentações territoriais e 
a baixa complementaridade entre os municípios na rede, fatores tão importantes quanto aos relativos à coesão.

18 O segundo critério ocorre pelas análises já utilizadas do recorte relativo do Baixo Amazonas como as do Programa Territórios da Cidadania (governos Lula e Dilma - 2003 a 2016) privilegiando redes de sujeitos locais através da articulação dos Conselhos de Desenvolvimento Territoriais Rurais (CODETER). Essa valorização das redes locais de sujeitos é de extrema importância para entendimento dos processos de des-reterritorialização (SAQUET, 2011) e as constantes disputas que ocorrem, interpretados aqui enquanto sistemas territoriais.

Os papéis reduzidos das sedes na divisão territorial do trabalho induzem manutenção de vínculos territoriais por classes populares, onde outras características são comuns entre os municípios do baixo Amazonas para embasar o caráter processual e relacional do modelo analítico relativo ao STUR: i) predomínio de repasses públicos na formação do PIB municipal; ii) predomínio do transporte fluvial na formação da rede urbana; iii) domínio da economia local pela fração relativa ao capital mercantil reforçando funções comerciais desempenhadas pelas sedes enquanto lugares centrais; iv) formação de uma economia popular com dinâmica específica realizando complementações através das relações urbano-ribeirinhas. Estas duas últimas características são centrais para apreensão de aspectos relacionais no território, detalhados no item seguinte. Usaremos o termo economia popular num sentido mais geral, caracterizando a multiplicidade de serviços informais e afazeres urbanos.

Com baixa formação de receita/arrecadação, os municípios do Baixo Amazonas tornamse dependentes do setor público através de Transferências Federais e estaduais (Tabela 2).

Tabela 2 - Transferências de Recursos Federais e Estaduais - 2018

\begin{tabular}{|c|c|c|c|c|c|c|c|}
\hline \multirow{2}{*}{$\begin{array}{l}\text { Subregião/ } \\
\text { municípios }\end{array}$} & \multicolumn{2}{|c|}{$\begin{array}{l}\text { Transferências Federais } \\
(\mathrm{r} \$ 1,00)\end{array}$} & \multicolumn{4}{|c|}{$\begin{array}{l}\text { Transferências estaduais }(r \$ 1,00) \\
\text { (repasses) }\end{array}$} & \multirow[t]{2}{*}{ PIB } \\
\hline & FPM & FUNDEB & ICMS & IPVA & IPI & ROYALTES & \\
\hline $\begin{array}{l}\text { Baixo } \\
\text { Amazonas }\end{array}$ & 114.306 .429 & 188.410 .862 & 102.706 .545 & 1.074 .641 & 287.982 & 1.433 .053 & 2.299 .502 \\
\hline Barreirinha & 15.766 .404 & 33.597 .278 & 9.258.164,94 & $21.370,66$ & 25.959 & 129.178 & 224.067 \\
\hline $\begin{array}{l}\text { Boa Vista do } \\
\text { Ramos }\end{array}$ & 11.824 .803 & 12.391 .113 & 7.546.687,54 & $10.616,02$ & 21.160 & 105.298 & 110.649 \\
\hline Maués & 23.649 .606 & 45.815 .744 & $25.753 .328,13$ & $185.609,55$ & 72.211 & 359.333 & 141.135 \\
\hline Nhamundá & 11.824 .803 & 13.426 .422 & $9.513 .263,16$ & $13.490,86$ & 26.675 & 132.737 & 135.660 \\
\hline Parintins & 31.532 .808 & 67.222 .985 & $31.240 .259,58$ & $789.421,67$ & 87.596 & 435.892 & 1.027 .190 \\
\hline $\begin{array}{l}\text { São Sebastião } \\
\text { do Uatumã }\end{array}$ & 7.883 .202 & 4.835 .230 & $7.576 .835,60$ & $11.296,21$ & 21.245 & 105.719 & 93.397 \\
\hline
\end{tabular}




\begin{tabular}{|l|l|l|l|l|l|l|l|}
\hline Urucará & 11.824 .803 & 11.122 .090 & $11.818 .006,25$ & $42.835,55$ & 33.137 & 164.895 & 297.858 \\
\hline
\end{tabular}

Fonte: Secretaria de Estado de Desenvolvimento Econômico, Ciência, Tecnologia e Inovação (SEDECTI-AM). Organizado pelo autor

21 O STUR é uma manifestação de contexto específico da economia popular em interação com o capital mercantil local, com intensa relação com o meio rural (produção e circulação constante). Isso o diferencia do circuito inferior da economia estudado por Santos (1979), cujo contexto metropolitano o coloca em intensa relação com o circuito superior de alta tecnologia, capacidade organizacional, investimento de capital, inexistente nas sedes urbanas do Baixo Amazonas.

Resumidamente, o Sistema Territorial Urbano-Ribeirinho (STUR) é composto pelo funcionamento e dinâmica da economia popular em cidades com dinâmicas fluviais e ribeirinhas. As redes de sujeitos do STUR realizam mediações e articulam a cidade a áreas de entorno sub-regional. Transportam produtos industrializados para interiores e retornam abastecendo o mercado urbano de recursos regionais. Receptam e processam produtos regionais na economia popular de bairros, consomem produtos, máquinas e insumos fornecidos pelo setor mercantil dominante, denominado como Sistema Territorial Urbano Fluvial (STUF). Essa reterritorialização do STUR molda a morfologia urbana pela formação de extensos bairros (ocupações irregulares), formando conjunto de fixos referenciais (nós multireticulares) que possibilitam suas atividades como as beiras de rio em bairros populares. Geralmente os sujeitos possuem atividades econômicas nos interiores e na cidade (economia dual), prevalecendo uso de embarcações pequenas e médias de madeira (BARTOLI, 2017; 2018a; 2018b)

o Sistema Territorial Urbano Fluvial (STUF) é composto pelo capital mercantil urbano articulado a escalas diversas na rede urbana. Empresas comerciais distribuidoras de produtos industrializados recebem e processam produtos regionais: entrepostos pesqueiros, madeireiras, fábricas processadoras de polpas de frutas, matadouro, frigoríficos, etc. Possuem domínio do comércio local de bens de consumo, máquinas e insumos, realizando relações escalares intensas com o exterior do sistema territorial (metrópoles regionais principalmente), articulando a rede urbana. O STUF impulsiona busca por recursos regionais fornecendo fluxos adjacentes, necessários para o funcionamento do STUR: gelo, combustível, alimentos, etc. Molda espaço intraurbano a seu favor construindo fixos referenciais como portos privados, galpões, etc., com uso de grandes embarcações de ferro (balsas principalmente).

As dinâmicas econômicas estagnadas refletem baixa variedade de atividades produtivas na cidade, mesmo em Parintins considerada cidade média de responsabilidade territorial (BARTOLI, et al 2019). Nesse contexto, o setor de comércio e serviços torna-se o principal gerador de empregos em sua maioria informais (tabela 3), dando corpo a uma densa economia popular.

Tabela 3: Produto Interno Bruto (PIB) por setor da economia e pessoal ocupado.

\begin{tabular}{|l|l|l|l|l|l|}
\hline Município & Agropecuária & Indústria & $\begin{array}{l}\text { Serviços } \\
\text { comércio }\end{array}$ & $\begin{array}{l}\text { Setor } \\
\text { Público }\end{array}$ & $\begin{array}{l}\text { Pessoal } \\
\text { ocupado }\end{array}$ \\
\hline Barrerinha & $23,51 \%$ & $3,08 \%$ & $16,51 \%$ & $56,59 \%$ & 954 \\
\hline
\end{tabular}




\begin{tabular}{|l|l|l|l|l|l|}
\hline Boa Vista do Ramos & $17,52 \%$ & $2,96 \%$ & $16,71 \%$ & $62,81 \%$ & 685 \\
\hline Maués & $15,05 \%$ & $4,61 \%$ & $21,33 \%$ & $58,56 \%$ & 3.574 \\
\hline Nhamundá & $17,44 \%$ & $4,32 \%$ & $19,22 \%$ & $59,02 \%$ & 888 \\
\hline $\begin{array}{l}\text { São Sebastião do } \\
\text { Uatumã }\end{array}$ & $26,54 \%$ & $4,66 \%$ & $16,04 \%$ & $54,76 \%$ & 536 \\
\hline Parintins & $28 \%$ & $4,57 \%$ & $25,85 \%$ & $41,58 \%$ & 6.974 \\
\hline Urucará* & --- & --- & --- & --- & 882 \\
\hline
\end{tabular}

Fonte: SEBRAE, 2019. Organizado pelo autor. Pesquisa não realizada em Urucará. (1979) os denomina como circuito inferior, presente onde se encontra a população pobre nas periferias de grandes e médias cidades, dinamizado enquanto modo de viabilizar o consumo. As produções com baixos graus de investimento em capital, tecnologia e organização - amiúde denominadas não modernas - encontram abrigo nas grandes manchas metropolitanas, constituindo uma força de concentração (SILVEIRA, 2010). O circuito inferior das pequenas cidades da Amazônia se diferencia das metrópoles. Requer metodologia específica para localidades com dinâmicas fluviais e ribeirinhas intensas e suas escalas com a rede urbana abordados no próximo subitem na proposta analítica do Sistema Territorial Urbano Ribeirinho (STUR). 
Tabela 4 - Microempresas, Micro-empreendedores individuais e Produto Interno Bruto (PIB)

\begin{tabular}{|l|l|l|l|}
\hline Município & $\begin{array}{l}\text { Microempresas } \\
\text { e Empresas de } \\
\text { Pequeno Porte* }\end{array}$ & $\begin{array}{l}\text { Micro-empreendedores } \\
\text { Individuais* }\end{array}$ & $\begin{array}{l}\text { Produto Interno Bruto } \\
\text { do Município** }\end{array}$ \\
\hline Barreirinha & 342 & 237 & $219.595,23$ \\
\hline $\begin{array}{l}\text { Boa Vista do } \\
\text { Ramos }\end{array}$ & 116 & 128 & $110.091,83$ \\
\hline Maués & 561 & 664 & $396.078,42$ \\
\hline Nhamundá & 155 & 185 & $133.330,88$ \\
\hline $\begin{array}{l}\text { S. Sebastião do } \\
\text { Uatumã }\end{array}$ & 107 & 99 & $94.782,26$ \\
\hline Urucará & & 1846 & $17.566,03$ \\
\hline Parintins & 1549 & & $1.024 .890,41$ \\
\hline
\end{tabular}

Fonte: SEBRAE*; IBGE cidades** - organizado pelo autor.

Em estudo sobre cidades pequenas, Endlich (2009, p.151) salienta que a forma e o volume do consumo assim como as transformações culturais e de valores que permeiam e estabelecem relações sociais são fatores relevantes para compreender o significado das pequenas cidades. A autora afirma que o declínio da sociedade rural é característica das cidades pequenas processo que acompanha mudanças no consumo e na diminuição da produção para subsistência, com criação de novos padrões comerciais (ENDLICH, 2009, p. 158). Relativos ao norte paranaense tais estudos de Endlich (2009) apontam que a implantação de rodovias e autopistas com intensificação do uso de automóveis implicou em acesso de populações a cidades vizinhas maiores, causando falência em comércios de pequenas cidades locais (perda de centralidade). Essa ampliação qualitativa e quantitativa do consumo fez com que a maioria das pequenas cidades perdesse centralidade em relação ao parâmetro do comércio existente em décadas anteriores. Isso não tem ocorrido nas cidades com dinâmicas fluviais e ribeirinhas que estamos analisando, cujos acessos às cidades maiores são bem mais difíceis, dispendiosos e demorados. Os setores comerciais da tabela 4 tem reforçado a centralidade dessas cidades pequenas, pois atendem uma enorme quantidade de comunidades que orbitam ao redor das sedes municipais, como nos exemplos de Urucará e São Sebastiao do Uatumã (figura 1). 
Figura 1 - padrão de deslocamentos e centralidades de Urucará e São Sebastiao do Uatumã.

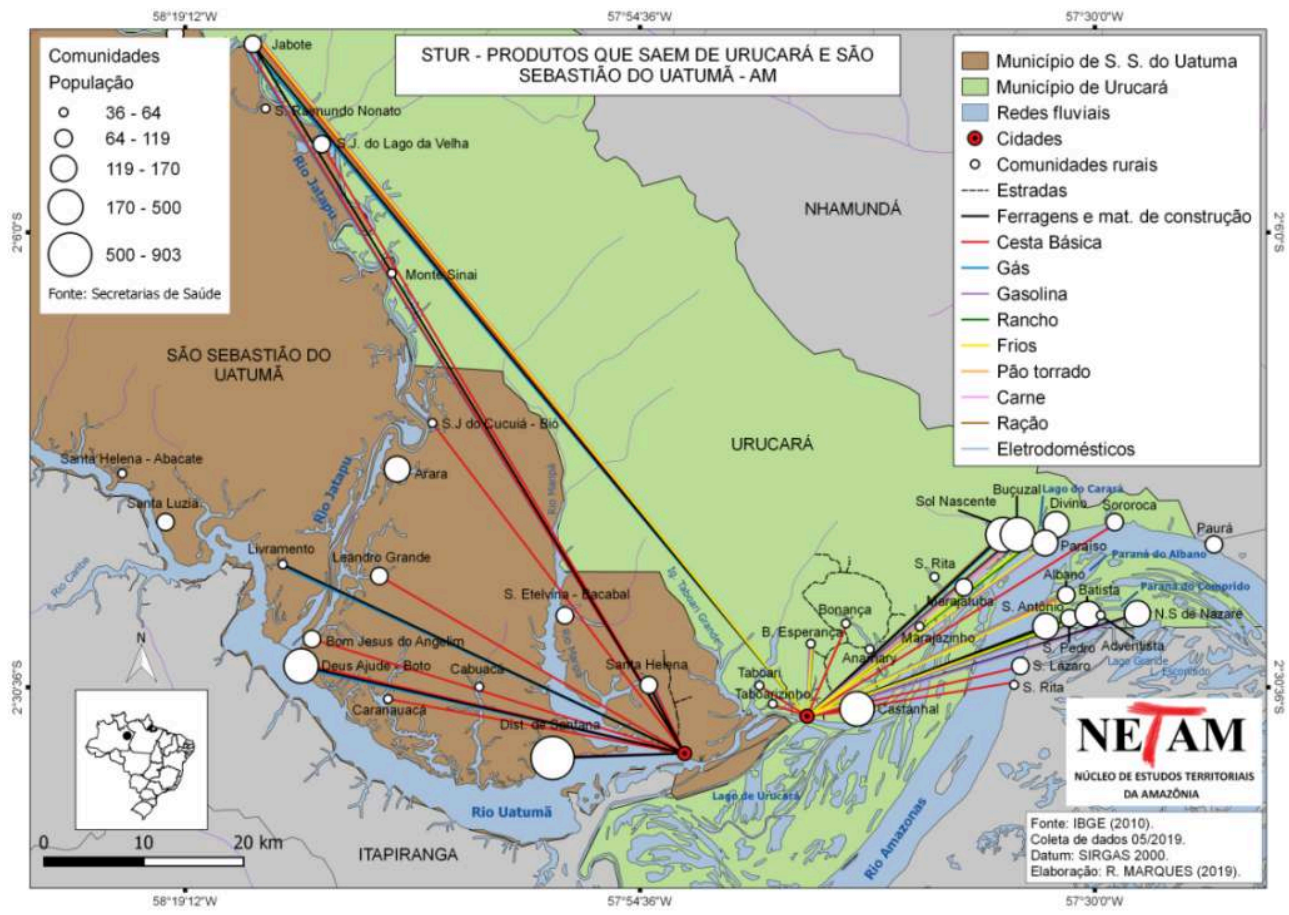

Fonte: trabalhos de campo (09/09/2019). aos olhos a ínfima parcela de pessoal ocupado, o que nos remete a pensar sobre a informalidade redinamizada na economia popular, base da proposta do modelo STUR. Parte da população costuma se deslocar com frequência para comunidades maiores e mais próximas às sedes, que também possuem pequenos comércios, com vendas de pequena quantidade, pois as compras mensais costumam ser feitas na cidade. Outra fração da população desloca-se com frequência menor para comunidades longínquas e de difícil acesso. É latente a densidade de comunidades próximas à sede e aos principais rios que interconectam com a metrópole e demais cidades maiores do entorno. A recente difusão de motores adaptados a embarcações rústicas ou a propagação de embarcações de alumínio mais rápidas tem sido fundamentais na circulação entre sedes comerciais e entornos diretos de influência.

Produção e consumo funcionam como forças de concentração e dispersão territorial. Qual tipo de consumo? Trata-se do consumo de itens básicos que possui seletividade pela desigualdade social, pela baixa existência de classes medias e altas nas cidades pequenas no entorno de Parintins. Obviamente, a difusão acelerada dos meios de comunicação é perceptível na paisagem "urbano-ribeirinha" na enorme quantidade de antenas digitais e parabólicas observadas sobre casas simples e palafitas, assim como as 
torres de comunicação em todas as cidades. No que tange aos hábitos alimentares, novidades foram encontradas nas aplicações de formulários nas beiras de rio, com a crescente quantidade de pão torrado, macarrão, ovos, frios (principalmente embutidos) e ultimamente o gás de cozinha, consumidos pelas comunidades (figura 1).

A figura 2 demonstra aspectos da estrutura territorial que condiciona usos do solo e sistemas de fluxos, ficando claro que a sub-região não possui ligações terrestres tanto a leste com a rede paraense (salvo pequenas estradas precárias de terra) como a oeste com a metrópole Manaus. $O$ transporte fluvial torna-se o principal mediador não só da construção da rede urbana, mas como mediação técnica de extrema importância na construção das territorialidades de diversas redes de sujeitos, com formação de sistemas territoriais.

Figura 2 - Estrutura Territorial - sub-região do Baixo Amazonas (2018)

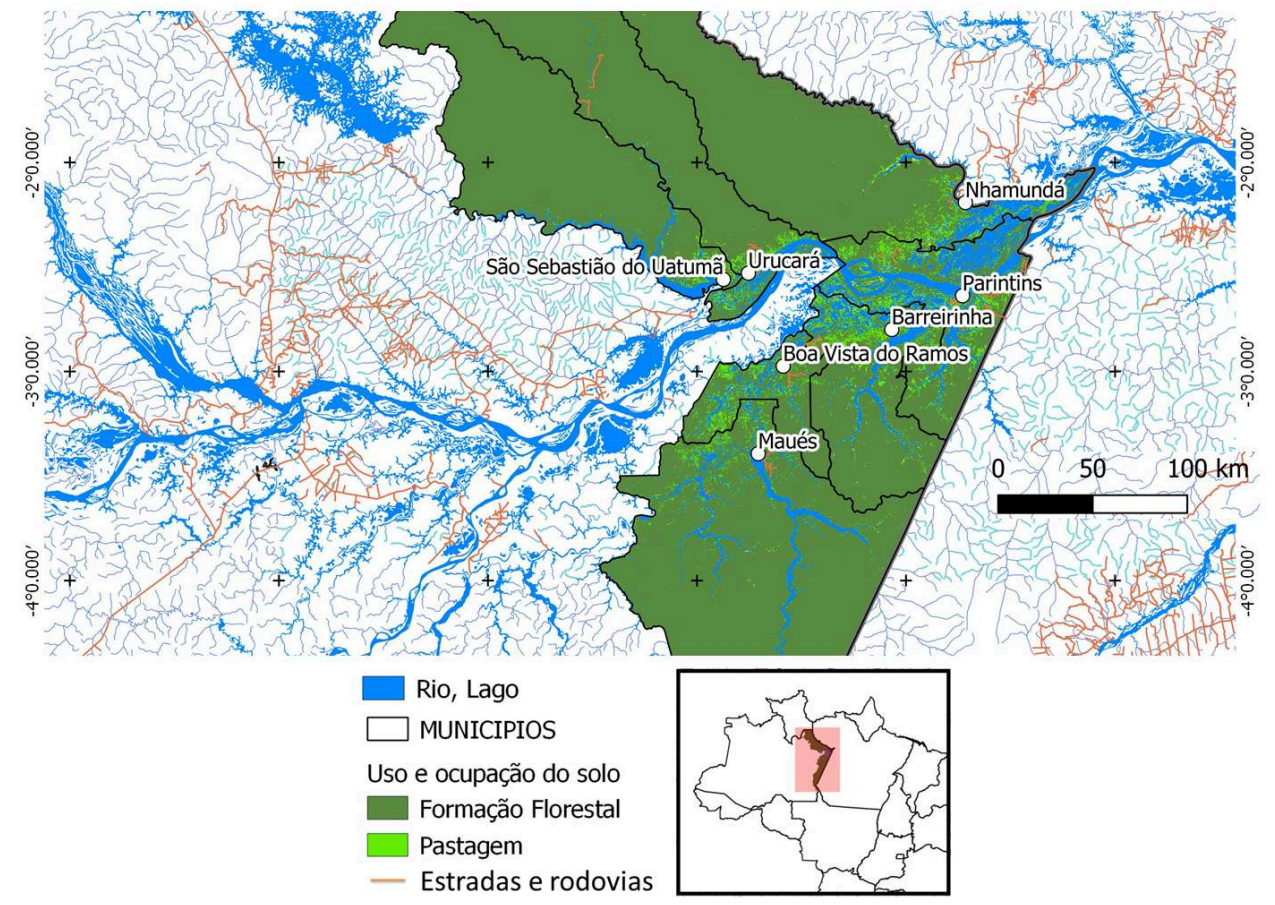

Fonte: IBGE, 2015; INPE, 2008 - elaborado por Heitor Pinheiro, 2010. DATUM:WGS1984.

Essa rarefação de Sistemas de engenharia de grande porte na sub-região como estradas, hidrelétricas, linhas de transmissão de energia e aeroportos, faz com que dois critérios sejam indispensáveis em sua análise: as territorialidades e dinâmicas fluviais e as ribeirinhas. Cabe aqui definição dos termos ribeirinho e fluvial. Usaremos o termo ribeirinho para indicar reprodução de práticas espaciais e territorialidades associadas a populações interioranas cada vez mais adaptadas ao meio urbano: forte referencial simbólico - cultural ao uso dos rios com temporalidades "lentas", usos lúdicos, atividades laborais de subsistência e circulação para complemento de renda (predomínio do valor de uso), formando micro-redes. o termo fluvial será utilizado indicando prevalência do capital mercantil como lógicas mais funcionais atreladas à circulação de mercadorias com uso de embarcações maiores, relacionadas a transporte de cargas (predomínio do valor de troca), nomeando o Sistema territorial dominante como STUF (Sistema Territorial Urbano-Fluvial). 


\section{Sistemas territoriais e a dinâmica sub-regional} topológico: conectando a cidade a pontos diversos do entorno sub-regional através da navegação fluvial e ribeirinha; ii) produção e configuração do espaço urbano em bairros oriundos de ocupações irregulares e de fragmentos no espaço intraurbano, constituindo fixos úteis para a navegação (beiras de rios, moradias, etc.); iii) econômico dual e complementar: sendo dinamizado principalmente pela economia popular mas em interação constante com as esferas de valorização do capital mercantil dominantes na cidade (saltos escalares que ultrapassam a sub-região); iv) organizacional e institucional: outros tipos de coalizão de sujeitos ganham relevância (cooperativas, associações, colônias de pescadores, etc.), mediando ações que se desdobram em práticas sobre o território; v) simbólico-cultural: traços da cultura cabocla e ribeirinha, indígena ou de conhecimentos populares são absorvidos e resignificados pela inserção ao processo urbano. em nossa área de estudo são embasadas por disputas que sinalizam a capacidade de ordenamentos territoriais estabelecidos por tais redes. Num sentido geral, as cidades pequenas devem ser interpretadas como marcas de escala de sua dimensão na divisão territorial do trabalho e da transformação do espaço em relação dialética e contínua com a luta de classes, inserindo-se no processo reticular da desigualdade geográfica do espaço (SPOSITO e JURADO, 2009).

descontinuidades, pois se fortaleceram através da acumulação histórica em cada nódulo da rede primordialmente fluvial durante os ciclos econômicos (explorando força de trabalho e habilidades dos setores populares). A proposta metodológica do Sistema Territorial Urbano-Ribeirinho (STUR) apresentada em Bartoli (2017, 2018a, 2018b, 2019) contribui para analisar como as redes de sujeitos locais de Parintins (AM) vem se reterritorializando na cidade devido à instabilidade dos ciclos econômicos que ocorreram na região, gerando êxodo rural e intensa circulação entre cidade e interiores. 
Figura 3: Fluxograma resumo das interações entre sistemas territoriais mediadores da influência urbana.

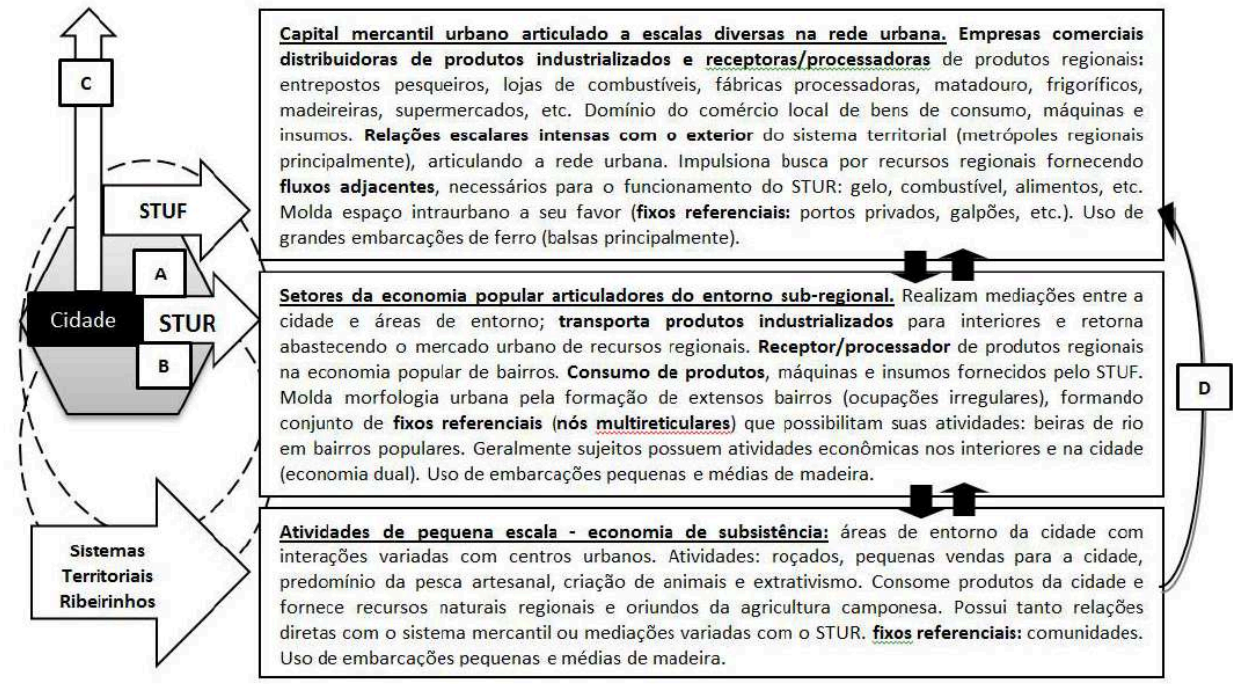

Legenda:

A - Tensões e conflitos: produç̃o do espaço urbano (ênfase nas beiras de rio).

B - Hibridização: elaboração de soluções criativas e adaptações técnicas em instrumentos de trabalho, moradia, tipos de embarcações e outras formas espaciais perceptíveis em bairros populares.C - saltos escalares diversos associado tanto ao capital mercantil, como da economia popular formando redes urbanas. D - extração de recursos regionais (inclusive areia e seixo para construção civil) realizada por grandes empresas comerciais da cidade; não há mediações ou processamento, mantendo sujeitos populares que abastecem tal fluxo em grau elevado de territorialidade passiva.

Fonte: BARTOLI (2018a) adaptado

Nas práticas espaciais do Sistema Territorial Urbano-Fluvial (STUF) uso de embarcações grandes de ferro vem conferindo vantagens ao obter produtos de Manaus (AM) e do Pará $^{4}$, o que torna as empresas médias de Parintins as maiores distribuidoras de alguns produtos na sub-região, como materiais de construção, combustíveis e alimentos industrializados (SILVA, 2018; BARTOLI, 2018a), reforçando sua centralidade e papel de cidade média de responsabilidade territorial (BARTOLI, et al, 2019).

Duas "forças" em direções de vetores partindo da cidade para interiores e no sentido inverso, dialeticamente, compõem a maneira com que o STUR realiza sua circunscrição espacial. A força centrípeta no STUR consiste no movimento contínuo de populações que migram na busca de benesses e melhorias que a cidade oferta, como no acesso a serviços, instituições de fomento/apoio à produção, bancos, mercados e tantas outras "facilidades" urbanas, indutoras de novos contextos de inserção de sujeitos na cidade. Assentados em ocupações irregulares, também necessitam “absorver" complementos recursivos dos interiores para complementar renda: madeira para moradia popular, barcos ou para pequena indústria moveleira; pescados; palha; piaçava; carne de caça ou quelônios, pequenas criações de gado, produtos do extrativismo, etc. A força centrífuga ocorre na busca do complemento dual: economia mercantil dominante influencia e incentiva a economia popular através de demandas por produtos (usufruindo de seus saberes em navegar, coletar, pescar, etc.) e compondo parte expressiva da economia urbana. A estrutura da cidade propicia condições para práticas espaciais fornecendo base de ação para que sujeitos atinjam localidades cada vez mais distantes, distribuindo assim produtos industrializados, dialogando com a tese da urbanização extensiva de Monte Mor (1994). 
No quadro 1 apresentamos os subsistemas territoriais no Baixo Amazonas, alguns não contemplando elementos da relação entre STUR/STUF, como casos dos que possuem saltos escalares com redes externas não estando submetidos às mediações locais (mineração principalmente). Deixaremos a atividade pecuária ausente do quadro pela enorme abrangência e sendo encontrada em todos os municípios como supracitado.

Quadro 1 - Principais Subsistemas Territoriais no Baixo Amazonas.

\begin{tabular}{|c|c|c|}
\hline Município & Subsistemas Territoriais & Escalas/redes \\
\hline \multirow[t]{2}{*}{ Barreirinha } & $\begin{array}{l}\text { - ausência de } \\
\text { especializações } \\
\text { produtivas. } \\
\text { - presença de15 pequenas } \\
\text { movelarias }\end{array}$ & - vendas pouco expressivas de móveis para Manaus \\
\hline & $\begin{array}{l}\text { - Intensa exploração de } \\
\text { madeira / ausência de } \\
\text { Planos de Manejo Florestal }\end{array}$ & - abastece STUR/STUF de Parintins \\
\hline $\begin{array}{l}\text { Boa Vista do } \\
\text { Ramos }\end{array}$ & $\begin{array}{l}\text { - ausência de } \\
\text { especializações } \\
\text { produtivas. } \\
\text { - produção de mel com } \\
\text { presença de cooperativa }\end{array}$ & - vendas pouco expressivas para Manaus \\
\hline \multirow{2}{*}{ Maués } & $\begin{array}{l}\text { - especialização produtiva: } \\
\text { - } 1^{\circ} \text { colocado na produção } \\
\text { de guaraná estadual }\end{array}$ & $\begin{array}{l}\text { - Influência de transnacionais de bebidas no } \\
\text { ordenamento territorial }\end{array}$ \\
\hline & $\begin{array}{l}\text { - presença de sistemas } \\
\text { territoriais de circuitos } \\
\text { ilegais: garimpos e drogas }\end{array}$ & - redes externas de poder \\
\hline Nhamundá & $\begin{array}{l}\text { - ausência de } \\
\text { especializações } \\
\text { produtivas. } \\
\text { - pequena atividade } \\
\text { pesqueira } \\
\text { (presença de Colônia e } \\
\text { sindicato de pescadores) }\end{array}$ & $\begin{array}{l}\text { - Fortemente polarizada por Manaus, Parintins e pela } \\
\text { rede paraense. }\end{array}$ \\
\hline \multirow[t]{2}{*}{$\begin{array}{l}\text { S. Sebastião } \\
\text { do Uatumã }\end{array}$} & $\begin{array}{l}\text { - especialização produtiva: } \\
\text { - maior polo naval de } \\
\text { embarcações de madeira } \\
\text { do estado / presença de } \\
\text { cooperativa naval }\end{array}$ & - vendas para todo o estado do Amazonas \\
\hline & $\begin{array}{l}\text { - cooperativa de } \\
\text { moveleiros }\end{array}$ & - vendas para Manaus \\
\hline
\end{tabular}




\begin{tabular}{|c|c|c|}
\hline \multirow{4}{*}{ Urucará } & $\begin{array}{l}\text { - } 2^{\circ} \text { maior produtor de } \\
\text { guaraná do estado }\end{array}$ & $\begin{array}{l}\text { - relações escalares externas com influência de grandes } \\
\text { empresas transnacionais fabricantes de bebidas }\end{array}$ \\
\hline & $\begin{array}{l}\text { - intensa atividade } \\
\text { pesqueira } \\
\text { (presença de Colônia e } \\
\text { sindicato de pescadores) }\end{array}$ & $\begin{array}{l}\text { - abastece STUR/STUF de Parintins e vendas de menor } \\
\text { quantidade para Maués e ocasionalmente Santarém } \\
\text { (PA) }\end{array}$ \\
\hline & $\begin{array}{l}\text { - pequena produção de } \\
\text { cacau }\end{array}$ & - vendas para Manaus \\
\hline & $\begin{array}{l}\text { - produção mineral / } \\
\text { extração de calcário } \\
\text { dolomítico }\end{array}$ & - Beneficiamento no município de Manacapuru (AM). \\
\hline \multirow{4}{*}{ Parintins } & $\begin{array}{l}\text { - Festival Folclórico de } \\
\text { projeção regional/ } \\
\text { nacional. } \\
\text { - consta como potencial } \\
\text { polo de economia criativa } \\
\text { com enorme quantidade } \\
\text { de artistas, estúdios, } \\
\text { escolas de arte e as } \\
\text { agremiações dos bumbás. }\end{array}$ & $\begin{array}{l}\text { - enorme complexidade escalar e reticular: patrocínios } \\
\text { de transnacionais (nacionais e estrangeiras); apoio } \\
\text { governamental estadual intenso; disputas locais pelo } \\
\text { controle político das agremiações; disputa de redes de } \\
\text { poder pelo controle de vendas de ingressos, bebidas, } \\
\text { direitos de imagem, etc.; espetacularização e } \\
\text { mercantilização da cultura local; migração de artistas } \\
\text { para todo o país para produções de carnavais e outras } \\
\text { festividades. } \\
\text { - aquecimento e intensificação da relação STUR/STUF. }\end{array}$ \\
\hline & $\begin{array}{l}\text { - polo moveleiro com } 53 \\
\text { empresas e diversas } \\
\text { pequenas indústrias } \\
\text { (olarias, polpa de frutas, } \\
\text { sorvetes, etc) }\end{array}$ & $\begin{array}{l}\text { - abastecimento local e pequena exportação para } \\
\text { Manaus }\end{array}$ \\
\hline & $\begin{array}{l}\text { - três entrepostos } \\
\text { pesqueiros/ frigoríficos de } \\
\text { médio porte; } \\
\text { - presença de Colônia e } \\
\text { sindicato de pescadores }\end{array}$ & $\begin{array}{l}\text { - Absorve pescado de toda sub-região; barcos } \\
\text { pesqueiros atingem o Baixo Solimões. } \\
\text { - empresas exportam para o sudeste peixes filetados. }\end{array}$ \\
\hline & $\begin{array}{l}\text { - significativa presença da } \\
\text { carpintaria naval em } 6 \\
\text { pequenos estaleiros. } \\
\text { - } 5 \text { pequenas empresas de } \\
\text { embarcações pequenas de } \\
\text { alumínio }\end{array}$ & $\begin{array}{l}\text { - escala local / manutenção da navegação doméstica no } \\
\text { STUR e STUF }\end{array}$ \\
\hline
\end{tabular}

Fonte: trabalhos de campo (fevereiro de 2019 a abril de 2020)

Cidades tornam-se verdadeiros pivôs das geometrias das grandes empresas e se tornam nodos das topologias das corporações globais (BERNARDES, 2001), cujas ações atingem localidades em regiões de dinâmica econômica reprimida na base da hierarquia urbana. Nas cidades como Maués e Urucará, afetadas por ações de grandes empresas, ocorrem 
inexpressivas alterações em suas estruturas internas, além de não corroborar com o desenvolvimento de complementaridades econômicas com a rede urbana. Essa influência direta de grandes empresas como na produção do guaraná e na extração de calcário, não incentivou criação de novas funções nas cidades para geração de trabalho novo. Várias outras atividades também não tem base de processamento nas cidades, caso do pescado e da madeira (quadro 1).

41 Parintins, devido ao afamado Festival Folclórico dos Bois-Bumbás Garantido e Caprichoso, sofre forte influência de investimentos de diversas empresas patrocinadoras e acirradas disputas pelo direito de imagens geradas no bumbódromo nas três noites de espetáculo. Da mesma forma, a inserção do Festival nesse circuito de espetacularização do evento tem gerado alterações nas formas e conteúdos da festividade, com ganhos estratosféricos aos setores dominantes onde o "mercado faz a festa na floresta" (NOGUEIRA, 2000), onde a "performance supera a festa de comemoração e se conduz em um produto de alta tecnologia, mercadoria adaptada ao gosto dos promotores" (AZEVEDO, 2010).

\section{Considerações Finais}

Resumindo nosso argumento, as articulações no interior de cada área municipal ocorrem principalmente nas relações entre STUR e STUF, nos fornecendo padrões comuns de circulação, consumo e usos do solo semelhantes entre as sedes e seus entornos. Sobre essa base territorial de tempo lento, ocorre ausência de agregação de valor aos produtos exportados sem especializações produtivas significativas. A modernização lenta e desigual do território amazônico tem aprofundado as desigualdades na rede urbana. Os sistemas técnicos se instalam seletivamente frente às características de populações que ainda se espraiam em padrões de uso do solo com baixa densidade demográfica, produtividade agrícola irrisória e papeis insuficientes de mediação dos núcleos urbanos. As "novidades" advindas dos sistemas técnicos dominantes demonstram ser pouco adaptadas às realidades locais, onde as pequenas atividades de alcance local do STUR podem ser potencializadas como criadoras de riqueza, sinalizando as reais necessidades das populações.

Outros fluxos atravessam a sub-região, onde embarcações de ferro de grande porte submetem a economia local à intensa penetração de produtos de outras regiões, submetendo o Baixo Amazonas aos vetores modernos de consumo. Das relações escalares emergem fragmentos em espaços opacos submetidos ao uso corporativo do território (SANTOS e SILVEIRA, 2001), que atingem uma economia de baixa diversidade ainda incapaz de gerar novas divisões territoriais do trabalho.

Pela estagnação econômica e baixa complexidade das economias urbanas no que tange aos papeis que as sedes desempenham, parte significativa do território amazonense fica à mercê de falta de comando regional da produção e da cooperação (SILVEIRA, 2010), delegando à maioria das pequenas cidades e seus entornos papeis produtivos reduzidos, cujas escassas rendas interioranas tem sido drenadas pelas redes da metrópole regional Manaus e pela rede paraense através do consumo de itens importados. 


\section{BIBLIOGRAFIA}

AZEVEDO, Luíndia, L. E. Boi Bumbá de Parintins (AM) y Çairé (PA), (re) configuraciones: Fiestas, EspectáculosI, Medios y Turismo. In: Punto Cero, año 15, no 20, 2010.

BARTOLI, E. O Retorno ao Território a partir da cidade: Sistemas Territoriais Urbano-Ribeirinhos em Parintins (AM). Presidente Prudente: PPGG / UNESP, 2017 (Tese de Doutorado). $1-16,2018 \mathrm{a}$.

Cidades na Amazônia, Sistemas Territoriais e a Rede Urbana. Mercator, v. 17, e17027, p.

Entre o Urbano e o Ribeirinho: Territorialidades Navegantes e Sistemas Territoriais em Parintins (AM). Espaço Aberto, PPGG - UFRJ, Rio de Janeiro, v. 8, n.2, p. 169-185, $2018 \mathrm{~b}$.

. Territorialidades Urbano-Ribeirinhas: o Sistema Territorial pesqueiro de Parintins (AM). GeoNorte, v.13, 2019.

Cidades Pequenas na Amazônia e Ordenamento Territorial: Redes de Sujeitos Locais e as Redes Urbanas de Urucará (AM) e São Sebastião do Uatumã (AM). Geoingá: Revista do Programa de Pós-Graduação em Geografia Maringá, v. 12, n. 1, p. 80-105, 2020a.

Cidades pequenas na Amazônia: sítio, situação e sistemas territoriais de Barreirinha (AM). Revista de Geografia e Ordenamento do Território (GOT), nº 19 (junho). Centro de Estudos de Geografia e Ordenamento do Território, p. 132-157, 2020b.

BARTOLI, E. SCHOR, T. OLIVEIRA, J.A., Cidades Médias na Amazônia: ampliando percepções sobre a responsabilidade territorial de Parintins (AM). Terra Plural, 2019.

BECKER, B. K. COSTA, R. H. SILVEIRA, C. D. B. (orgs.). Abordagens Políticas da Espacialidade. Rio de Janeiro: UFRJ, 1974.

. A Geopolítica na virada do Milênio: Logística e Desenvolvimento Sustentável. In: CASTRO, Iná Elias de. Geografia e política: Território, escalas de ação e instituições. Rio de Janeiro: Bertrand Brasil, 2005.

. A Urbe Amazônida. Rio de Janeiro: Garamond, 2013.

BERNARDES, Adriana. A contemporaneidade de San Pablo: produção de

informações e novo uso do território brasileiro. Tese (Programa de Pós-Graduação em Geografia Humana) - Universidade de São Paulo, São Paulo, 2001.

BITOUN, J. Tipologia das cidades brasileiras e políticas territoriais: pistas para reflexão. in: . MIRANDA, L. (orgs.). Desenvolvimento e Cidades: Contribuições para o Debate sobre as Políticas de Desenvolvimento Territorial. Rio de Janeiro: FASE, Observatório das Metrópoles, 2009.

BRANDÃO, Carlos Antônio. Território e Desenvolvimento: as múltiplas escalas entre o local e o global. Campinas: Editora da Unicamp, 2007.

BROWDER J.O. GODFREY, B.J. Cidades na Floresta. Manaus: EDUA, 2006.

CORRÊA, R. L. A Periodização da Rede Urbana na Amazônia. In: Estudos sobre a rede urbana. Rio de Janeiro: Bertrand Brasil, 2006. p. 181-253.

ENDLICH, A. M. Pensando os papéis e significados das pequenas cidades. São Paulo: Ed. Unesp, 2009. 
FERNANDES, Ana Cristina. Conhecimento, desenvolvimento regional e as cidades brasileiras. in: BITOUN, J. MIRANDA, L. Desenvolvimento e Cidades no Brasil. Contribuições para o Debate sobre as Políticas Territoriais. Recife: FASE: Observatório das Metrópoles, 2009.

FREITAS, Carlos Alberto. TCC Parintins-AM, 2018. Monografia de Conclusão de Curso Licenciatura em Geografia) - Universidade do Estado do Amazonas, UEA/CES/Parintins, 2018.

GENTIL, Janete. A noção do Urbano em Áreas de Fronteira: uma revisão teórica. in: Seminário sobre Amazônia: a fronteira agrícola 20 anos depois. Belém: Museu Paraense Emílio Goeldi, 1988.

MONTE-MÓR, R.L. A Urbanização Extensiva e Lógica de Povoamento. SANTOS, Milton et. al. (orgs.) Território, globalização e fragmentação. São Paulo: Hucitec/Anpur, 1994 (pp. 169-181).

MORAES, A. Embalando Mercados em Redes Urbanas: alimentação e pesca articulando cidades na Amazônia brasileira. in: SCHOR, T. (org.). Dinâmica Urbana na Amazônia - vol. 1. Manaus: Valer, 2014.

MORAES, André Oliveira; SCHOR, Tatiana. ALVES-GOMES, José. O Mercado de Bagres e a Configuração da Rede Urbana no Alto e Médio Solimões, Amazonas, Brasil. Caderno Prudentino de Geografia. v.1, n.32, p. 93-110, 2010.

NOGUEIRA, W. O Mercado faz a festa na floresta. In: Somanlu: Revista de Estudos Amazônicos do Programa de Pós-graduação em Sociedade e Cultura na Amazônia da Universidade Federal do Amazonas. Ano 1, n. 1 (2000 - ). Manaus: Edua/Capes, 2000.

SANTOS, M. A urbanização Brasileira. São Paulo: Hucitec, 1993. Economia Espacial. São Paulo: Edusp, 2007.

SANTOS, M. SILVEIRA, M. L. Brasil: território e sociedade no limiar do século XXI. Rio de Janeiro: Record, 2003.

SAQUET, Marcos Aurélio. Por uma Geografia das Territorialidades e das Temporalidades: uma concepção multidimensional voltada para a cooperação e para o desenvolvimento territorial. São Paulo: Outras Expressões, 2011.

SEDECTI, Secretaria de Estado de Desenvolvimento Econômico, Ciência, Tecnologia e Inovação. Anuário Estatístico Amazonas, 2018.

SERRÃO, Arenilton Monteiro. Colônias agrícolas e campesinato: raízes de uma nova territorialidade no médio rio Amazonas, município de Urucará-Am. / Arenilton Monteiro Dissertação (Mestrado em Geografia) - Universidade Federal do Amazonas, 2017.

SILVA. Sylvio Bandeira de Mello e. Cidades pequenas e médias: reflexões teóricas e aplicadas. In: Cidades médias e pequenas: teorias, conceitos e estudos de caso. / Diva Maria Ferlin Lopes, Wendel Henrique (organizadores). - Salvador: SEI, 2010. 250 p. il. (Série estudos e pesquisas, 87). SILVA, Fernando. Capital Mercantil, Transportes Fluviais e a Rede Urbana Sub-Regional de Parintins-AM. Parintins-AM, 2018. Monografia de Conclusão de Curso Licenciatura em Geografia) - Universidade do Estado do Amazonas, UEA/CES/Parintins, 2018.

SILVEIRA, M.L. Região e Globalização: pensando um esquema de análise. Redes. Revista do Desenvolvimento Regional, vol. 15, núm. 1, enero-abril, 2010, pp. 74- 88.

SPOSITO, E. S. ; JURADO DA SILVA, P. F. Cidades Pequenas, perspectivas teóricas e Transformações Socioespaciais. Jundiaí: Paco editorial, 2013.

SUFRAMA. Relatório de Gestão. Ministério do Desenvolvimento Indústria e Comércio Exterior, 2007. Disponível em http://www.suframa.gov.br/suframa_relatorio_de_gestao.cfm 
WALLERSTEIN, I. The relevance of the concept of semiperiphery to the analysis of Southern Europe. In: ARRIGHI, G. (ed.) Semiperipheral development: the politics of Southern Europe in the twentieth century. Beverly Hills: Sage publications, 1985.

\section{NOTAS}

1. Denominamos no presente texto como Baixo Amazonas, a sub-região de planejamento composta pelos municípios de Urucará, Boa Vista do Ramos, Barreirinha, Maués, São Sebastião do Uatumã, Nhamundá e Parintins.

2. O presente texto compõe pesquisa em fase de conclusão atrelada à bolsa produtividade da Universidade do Estado do Amazonas (UEA), com intuito de estudar os municípios que compõem a sub-região do Baixo Amazonas.

3. O presente artigo faz parte das primeiras etapas da análise empreendida pelo Núcleo Estadual de Integração e Desenvolvimento da Faixa de Fronteira do Estado do Amazonas (NIFFAM), relativa à sub-região do Baixo Amazonas. O NIFFAM foi criado por um grupo multi-institucional com a tarefa de articular ações de integração e desenvolvimento na região fronteiriça do Amazonas. A análise no Baixo Amazonas ocorre com parceria da Universidade do Estado do Amazonas (UEA - campus de Parintins), através do Núcleo de Estudos Territoriais do Amazonas (NETAM) que vem realizando estudos sobre os municípios do Baixo Amazonas no Projeto intitulado Rede urbana, Tipologia de Cidades e Sistemas Territoriais Urbano-ribeirinhos no Baixo Amazonas.

4. - balsas de carga, balsas de combustíveis, empurradores, barcos tanque de gasolina, barcos grandes de ferro, lanchas e iates de veraneio. Deixaremos de lado os cargueiros utilizados para transporte de produtos produzidos pelo Polo industrial de Manaus e os transatlânticos de turistas que ancoram em Parintins, pois exigiriam ampliação dos sistemas atrelados a outras frações do capital, mas sendo tema de estudos frutíferos em pesquisas futuras.

\section{RESUMOS}

$\mathrm{O}$ artigo objetiva traçar o perfil socioeconômico dos municípios da sub-região do Baixo Amazonas (AM) apresentando as características comuns, as articulações e as fragmentações no desenvolvimento desigual da rede urbana. O primeiro item apresenta bases teóricas sobre o processo de urbanização regional com reflexões sobre a urbanização incompleta e a análise de dados socioeconômicos reveladores da estagnação dos municípios. O segundo item apresenta dados secundários sobre o comércio, os serviços, a população e o PIB os quais, junto a constatações de campo e à análise de mapas, evidenciam padrões de deslocamento e centralidade das cidades. O terceiro item apresenta o modelo teórico metodológico relativo ao Sistema Territorial Urbano-Ribeirinho (STUR), o qual compreende a análise da dinâmica de setores populares da economia urbana em interação com o capital mercantil. Para tanto foi considerado o perfil municipal de consumo e produção; as atividades de complementação de renda; a circulação entre as cidades e os interiores e os subsistemas territoriais existentes. $O$ artigo conclui que há um padrão espacial semelhante no ordenamento territorial das cidades assim como fragmentações e descontinuidades causadas por dinâmicas escalares. 
This paper aims to outline the socioeconomic profile of the municipalities in the sub-region of Baixo Amazonas (AM), demonstrating common characteristics, articulations and fragmentations in the uneven development of the urban network. At the first moment, it was made theoretical considerations about the regional urbanization process, showing thoughts on incomplete urbanization through socioeconomic data that show the municipalities' stagnation. In the second item we analyze secondary data on trade, services, population and GDP, which together with field findings and map analysis describes patterns of displacement and centrality of cities. In the third item, it's presented the theoretical methodological model related to the Sistema Territorial Urbano-Ribeirinho (STUR, Urban-Riverine Territorial System), which comprises the dynamics of popular sectors of the urban economy in interaction with mercantile capital. Thus way, at showing the main territorial subsystems existing in the municipalities, the paper concludes that there is a similar spatial pattern in the territorial ordering of cities as well as fragmentations and discontinuities caused by scalar dynamics.

Cet article analyse le profil socio-économique des municipalités de la sous-région du Bas Amazonas (AM) en présentant ses caractéristiques communes, ses articulations et ses fragmentations à l'intérieure du développement inégale du réseau urbain. Après avoir présenté les bases théoriques associées à l'urbanisation incomplète, on utilise des données secondaires, des recours cartographiques et le travail de terrain pour montrer les modèles de centralité et de déplacement des villes. A la suite, on expose le système territorial urban-riverain (STUR) afin d'expliquer les rapports entre les secteurs populaires de l'économie urbaine et le capital mercantile. On peut conclure par l'existence d'un modèle spatial à régler les villes amazoniennes.

El artículo tiene como objetivo trazar el perfil socioeconómico de los municipios de la subregión del Baixo Amazonas (AM), presentando las características comunes, las articulaciones y las fragmentaciones en el desarrollo desigual de la red urbana. El primer tema presenta bases teóricas sobre el proceso de urbanización regional con reflexiones sobre la urbanización incompleta y el análisis de datos socioeconómicos que evidencian el estancamiento de los municipios. El segundo tema presenta datos secundarios sobre el comercio, los servicios, la población y el PIB, que junto con lo que se constató en campo y el análisis de mapas muestran patrones de desplazamiento y centralidad de las ciudades. El tercer tema presenta el modelo metodológico teórico relacionado con el Sistema Territorial Urbano-Ribeirinho (STUR), este sistema comprende el análisis de la dinámica de los sectores populares de la economía urbana en interacción con el capital mercantil. Para eso, se consideró el perfil municipal de consumo y producción; las actividades complementarias de ingresos; la circulación entre ciudades e interiores y los subsistemas territoriales existentes. El artículo concluye que existe un patrón espacial similar en el ordenamiento territorial de las ciudades, así como fragmentaciones y discontinuidades provocadas por las dinámicas escalares.

\section{ÍNDICE}

Palavras-chave: cidades, urbanização, Baixo Amazonas, Centralidades, sistemas territoriais.

Palabras claves: ciudades, urbanización, Bajo Amazonas, centralidades, sistemas territoriales.

Mots-clés: villes, l'urbanisation, Bas Amazonas, centralités, systèmes territoriaux

Keywords: cities, urbanization, Lower Amazon, centralities, territorial systems. 


\section{AUTOR}

\section{ESTEVAN BARTOL}

Universidade do Estado do Amazonas, Centro de Estudos Superiores de Parintins, Professor Adjunto. Email: ebartoli11@gmail.com 